\title{
Corneal transplant during COVID-19 pandemic: the Italian Eye Bank national report
}

\author{
Francesco Aiello (1) - Federico Genzano Besso • Giulio Pocobelli • \\ Gabriele Gallo Afflitto - Rossella Anna Maria Colabelli Gisoldi • Carlo Nucci • \\ Diego Ponzin • on behalf of Italian Society Eye Bank Group (SIBO).
}

Received: 21 December 2020/Accepted: 10 May 2021/Published online: 24 May 2021

(C) The Author(s) 2021

\begin{abstract}
To investigate the impact of Coronavirus Disease-2019 lockdown on the Italian Eye Bank organization. In this national retrospective, multicentric, cohort study, data from the Italian Eye Bank during both the lockdown and the first month after the lockdown period were retrieved. We compared the Italian Eye Bank metrics with the same timeframe of 2019 and 2018. Data from 13 out of 13 (100\%) Italian Eye Banks were included in the analysis. A statistically significant reduction in the number of donor corneas retrieved in 2020 was found as compared to the same period in 2019 and in 2018, respectively
\end{abstract}

F. Aiello $(\bowtie) \cdot$ G. Pocobelli · G. Gallo Afflitto ·

C. Nucci

Ophthalmology Unit. Department of Experimental

Medicine, University of Rome "Tor Vergata", Rome,

Italy

e-mail: francescoaiello@hotmail.com;

francesco.aiello@ptvonline.it

G. Pocobelli

e-mail: giulio.pocobelli@gmail.com

F. Genzano Besso

Eye Bank of Piedmont, SSD Tissue Banks and

Biorepository, Città della Salute e della Scienza, Torino, Italy

R. A. M. Colabelli Gisoldi

Ophthalmology Unit, San Giovanni Addolorata Hospital,

Rome, Italy

D. Ponzin

The Veneto Eye Bank Foundation, Venice, Italy
$(2020=1284 ; 2019=3088 ; 2018=3221 ;$ ANOVA: $p<0.0001)$. Only 534 corneas have been distributed by Eye Banks during the COVID-19-lockdown period $(2020=534 ; 2019=1220 ; 2018=1237$. ANOVA: $p<0.0001)$. Similarly, the number of wasted corneas due to postponed or cancelled surgeries was 421 , resulting in a considerable increase as compared to the previous 2 years $(2020=421 ; 2019=67 ; 2018=84$; ANOVA: $p=0.0035)$. Overall, 45 donor corneas were rejected in accordance with the guidance of the Italian National Health Institute Italian National Transplant Centre (CNT). SARS-CoV-2 pandemic has profoundly affected every social and medical field, including the Eye Bank procurement and distribution programs. The current data collected from all the Italian Eye Banks highlights the present and the forthcoming difficulties that the Eye Bank community is going to experience, as for the ongoing pandemic.

Keywords Eye banks activities - Corneal transplant $\cdot$ COVID-19 $\cdot$ SARS-CoV-2 $\cdot$ Lockdown

\section{Introduction}

On December 31, 2019, China notified the World Health Organization (WHO) of a pneumonia outbreak of unknown aetiology. The causative agent was named as Severe Acute Respiratory Syndrome-Coronavirus2 (SARS-CoV-2), responsible for the Coronavirus 
Disease-2019 (COVID-19). (Zhu et al. 2020; Aiello et al. 2020).

Italy was the first western European country affected by the pandemic. As of March 9, 2020, the Italian Government imposed a national quarantine, restricting the movements of the population in response to the growing epidemic of COVID-19. (Buonomo et al. 2020) This decision drastically reduced healthcare provision, with disruption and cancellation of non-urgent medical procedures, including elective corneal transplant surgeries (Olivia Li et al. 2020; Vanni et al. 2020b; Busin et al. 2020) Gain et al. demonstrated that the Italian Eye Bank Institution is the second main procurer of corneal grafts after the United States of America, with $250 \bullet 10^{-6}$ cornea donations per capita per year, rendering it one of the most prolific Eye Bank Institution throughout the world. (Gain et al. 2016).

Hence, the aim of this study is to analytically explore the COVID-19 impact on the Italian Eye Bank organization, as a reliable index of the COVID-19 effect on the Eye Bank activity worldwide.

\section{Material and methods}

We collected data from the Italian Society of Eye Banks (SIBO), the reference board in charge of the coordination of the 13 Eye Banks in Italy (Società Italiana Banche degli Occhi 2000).

We compared the number of corneal transplant procedures performed during the Italian lockdown period (March to April 2020) together with the first month post lockdown (May 2020) as compared with the same timeframe in both 2019 and 2018. All the available information regarding the number, type and setting (i.e., emergency $v$ s. elective procedure) of performed corneal transplant surgeries was analysed. In addition, we investigated the number of wasted tissues (recovered, processed and expired) and the number of tissues collected from donors who were subsequently found to be positive to COVID-19. Furthermore, we collected data regarding the number of corneas already stored in the eye banks that had expired and were wasted, as well as the number of tissues that have been booked by surgeons but sent back due to unexpected cancellation in 2020, 2019 and in 2018 during the same aforementioned months.
We also evaluated the eye bank activity in the month following the end of the lockdown period compared with the one of both 2019 and 2018, as an index of the resumption of both clinical and surgical activity throughout the country. Finally, we compared the corneal transplant surgical activity during the lockdown period with the one performed in the subsequent month. Each eye bank provided anonymised and aggregate data and thus the institutional review board ruled that ethics approval was not required for this study.

\section{Statistical analysis}

The statistical analysis was performed using the SPSS software version 26.0 (SPSS Inc.). Unmatched, nonparametric continuous variables were compared using the Mann-Whitney test. The Wilcoxon matched-pairs signed rank test was used to compare matched, nonparametric continuous variables. Analysis of Variance (ANOVA) test was used for unmatched, parametric, continuous variables. Friedman test was used for matched, non-parametric, continuous variables. For unadjusted comparisons, a 2-sided $\alpha$ of less than 0.05 was considered statistically significant.

\section{Results}

In this national multicentre, retrospective cohort study, data from 13 out of $13(100 \%)$ Italian eye banks were included in the analysis. Notably, Eye Banks from northern Italy (Lombardia, Veneto, Piemonte and Emilia-Romagna), located in those Italian regions more affected by COVID-19 pandemic, were adequately represented, accounting for the $38 \%$ of the entire cohort. Eye Banks from central and southern Italy accounted for the $46 \%$ and the $15 \%$, respectively.

\section{Italian corneal transplant machinery data during the lockdown period}

Overall, from the 1st of March, 2020 to the 30th of April, 2020, (months of lockdown) 1284 donor corneas had been collected and harvested. After proper investigation, only 31 grafts $(2 \%)$ were found 
to not be feasible to transplant due to the risk of SarsCoV-2 contamination, in accordance to the guidance of the Italian National Health Institute/Italian National Transplant Centre (CNT) (donor with proved COVID19 or donor with unproved infection but pathological history consistent of COVID-19). (Istituto Superiore di Sanità 2020) A statistically significant reduction was found in the number of retrieved corneas in 2020 as compared with the one relative to the same period in $2019(-58 \%)$ and in $2018(-60 \%)$, respectively (Table 1).

In Italy, only 534 corneas were distributed during the COVID-19-lockdown period, with a significant reduction when compared to those of $2019(-56 \%)$ and $2018(-57 \%)$. In particular, 247 (46\%) penetrating keratoplasties (PKs), 49 (10\%) anterior lamellar keratoplasties (ALKs) and $238(45 \%)$ endothelial keratoplasties (EKs) were recorded. Significant differences emerged from the comparison of 2020 PKs, ALKs and EKs data with both the 2019 and the 2018 ones, as shown in Table 1 (PK reduction: $-52 \%$ in 2019 and $-58 \%$ in 2018; ALK reduction: $-74 \%$ in 2019 and $-69 \%$ in 2018; EK reduction: - 58 in 2019 and $-58 \%$ in 2018).

Thirty (5\%) of those 534 surgeries were performed as emergency procedures (EP) with no significant difference with regards to the ones of the 2 preceding years (Table 1).

The number of cancelled transplants during the COVID-19 lockdown period reached the number of 103. On the other hand, in the same timeframe of 2019 , only 27 cancelled procedures were registered, and 35 in 2018. The analysis of variance revealed a significant difference (ANOVA: $p<0.0001$ ). Similarly, the number of wasted corneas (not used) due to delayed or cancelled surgeries was 421 , resulting in a considerable increase as compared to the previous 2 years $(2019:+528 \% ; 2018:+401 \%)$. The Friedman test hence resulted in a significant difference (ANOVA: $p=0.0035$ ). In addition, the requested and delivered albeit not implanted corneal tissues reached a total of 9 during the lockdown period. This number resulted to be lower than the one recorded in 2019 and in 2018 (26 and 24, respectively) ( $p=0.1024)$.

\section{Corneal transplant data during the first month after the lockdown period}

The total number of donor corneas collected and harvested from May 1, 2020 to May 31, 2020 was 850. This value was notably lower than the one registered in the same period of both $2019(-49 \%)$ and 2018 $(-42 \%)$ (ANOVA: $p=0.0003)$.

In the aforementioned timeframe, 14 tissues (2\%) were found to be retrieved from donor with proved COVID-19 or donor with unproved infection but pathological history consistent of COVID-19.

In the first month post-lockdown, 430 corneal transplants were performed, with a significant reduction as compared to the same period of $2019(-42 \%)$ and 2018 ( $-40 \%$ ) (ANOVA: $p<0.0001)$. Specifically, the most statistically significant fall was registered in the number of PKs and EKs, while no

Table 1 Corneal transplant metrics during the lockdown period (March and April, 2020) as compared to the same timeframe in 2019 and 2018

\begin{tabular}{llllr}
\hline & March-April 2020 & March-April 2019 & March-April 2018 & $p$ \\
\hline $\mathrm{N}^{\circ}$ of received corneas & 1284 & 3088 & 3221 & $<0.0001$ \\
$\mathrm{~N}^{\circ}$ of Surgical Procedures & 534 & 1220 & 1237 & $<0.0001$ \\
$\mathrm{~N}^{\circ}$ of PKs & 247 & 519 & 582 & 158 \\
$\mathrm{~N}^{\circ}$ of ALKs & 49 & 188 & 572 & 0.0013 \\
$\mathrm{~N}^{\circ}$ of EKs & 238 & 571 & 46 & $<0.0001$ \\
$\mathrm{~N}^{\circ}$ of EPs & 30 & 59 & 35 & 0.1282 \\
$\mathrm{~N}^{\circ}$ of cancelled procedures & 103 & 27 & 24 & 0.0001 \\
$\mathrm{~N}^{\circ}$ of requested albeit not transplanted corneas & 9 & 26 & 84 & 0.1024 \\
$\mathrm{~N}^{\circ}$ of waisted grafts & 421 & 67 & 0.0035 \\
\hline
\end{tabular}

$P K$ penetrating keratoplasty; $A L K$ Anterior lamellar keratoplasty; $E K$ endothelial keratoplasty 
statistical differences emerged from the comparison of the total amount of ALKs, and EPs performed, as shown in Table 2 (PK reduction: $-54 \%$ when compared with 2019 and $-52 \%$ in 2018; ALK reduction: $-32 \%$ when compared with 2019 and - $32 \%$ in 2018; EK reduction: - 34\% when compared with 2019 and $-31 \%$ in 2018; EP reduction: - 51\% when compared with 2019 and $-50 \%$ compared with 2018).

Significant difference emerged from the analysis of the amount of both the requested and delivered albeit not implanted corneal tissues $(2020=0 ; 2019=7$; $2018=10$; ANOVA: $p=0.0237$ ) while none was found regarding the proportion of cancelled procedures $(2020=8 ; 2019=7 ; 2018=20 ;$ ANOVA: $p=0.6368)$. Overall, 65 stored corneas were lost for not being used within the expected period, a percentage marginally higher than that of the same period in 2019 and $2018(2020=65 ; 2019=40 ; 2018=58$; ANOVA: $p=0.9138)$.

\section{Lockdown period vs. first month after the lockdown period}

The comparative analysis of the data related to the lockdown period as compared to the one of the first month post-lockdown revealed no statistically significant differences in terms of number of donor corneas not feasible to transplant per high-COVID-19-transmission risk and total number of ALKs, EKs and EPs, as shown in Table 3. In April, the number of surgical procedures appeared to be subjected to a significant reduction when compared to both March and May $(p=0.0028)$. Even the amount of collected corneas appeared to be lower in April than March and May $(p=0.0038)$. Fewer corneal grafts were lost in May than during the preceding 2 months (421 vs. 65; $p=0.0403$ ). No differences were found in the total number of cancelled procedures $(p=0.0608)$ while a lower amount of not-transplanted corneal grafts was registered in May than during the preceding 2 months $(p=0.0302)$.

\section{Discussion}

This comprehensive, national cohort study provides a comprehensive and in-depth overview of the impact of COVID-19 pandemic on the Italian National Eye Bank organization and on the related surgical activity. Italy has been one of the first western countries to be affected by SARS-CoV-2 with subsequent restrictions to control its outbreak. (Romano et al. 2020; Vanni et al. 2020a).

Our survey, which included data from all the Italian Eye Bank establishments, confirms that their activities underwent profound changes throughout the country with unexpected sequelae to both the collection of eye tissues (i.e., tissues collection and harvesting), their distribution to the ophthalmology wards and their usage for surgical purpose.

It must be considered that, apart from a small percentage of cases (i.e., corneal perforation), corneal transplants are in general elective surgeries. In Italy, starting from March 9, 2020 (the starting date of the

Table 2 Corneal transplant metrics during the first month after the lockdown period (May, 2020) vs. May, 2019 and May, 2018

\begin{tabular}{llllr}
\hline & May 2020 & May 2019 & May 2018 & $p$ \\
\hline $\mathrm{N}^{\circ}$ of received corneas & 850 & 1655 & 1477 & 717 \\
$\mathrm{~N}^{\circ}$ of Surgical Procedures & 430 & 746 & 310 & 0.0003 \\
$\mathrm{~N}^{\circ}$ of PKs & 150 & 325 & 80 & 0.0001 \\
$\mathrm{~N}^{\circ}$ of ALKs & 54 & 80 & 327 & 0.2307 \\
$\mathrm{~N}^{\circ}$ of EKs & 226 & 341 & 34 & 0.0144 \\
$\mathrm{~N}^{\circ}$ of EPs & 17 & 35 & 20 & 0.6832 \\
$\mathrm{~N}^{\circ}$ of cancelled procedures & 8 & 7 & 10 & 0.6368 \\
$\mathrm{~N}^{\circ}$ of requested albeit not transplanted corneas & 0 & 7 & 58 & 0.0237 \\
$\mathrm{~N}^{\circ}$ of wasted Grafts & 65 & 40 & 0.9138 \\
\hline
\end{tabular}

$P K$ penetrating keratoplasty; $A L K$ Anterior lamellar keratoplasty; $E K$ endothelial keratoplasty 
Table 3 Corneal transplant metrics during the lockdown period (March and April, 2020) as compared to May, 2020

\begin{tabular}{|c|c|c|c|c|}
\hline & March 2020 & April 2020 & May 2020 & $p$ \\
\hline $\mathrm{N}^{\circ}$ of received corneas & 789 & 495 & 850 & 0.0038 \\
\hline $\mathrm{N}^{\circ}$ of COVID-19 positive donor corneas & 21 & 10 & 14 & 0.6514 \\
\hline $\mathrm{N}^{\circ}$ of surgical procedures & 379 & 155 & 430 & 0.0028 \\
\hline $\mathrm{N}^{\circ}$ of PKs & 188 & 59 & 150 & 0.0337 \\
\hline $\mathrm{N}^{\circ}$ of ALKs & 30 & 19 & 54 & 0.0743 \\
\hline $\mathrm{N}^{\circ}$ of EKs & 161 & 77 & 226 & 0.2938 \\
\hline $\mathrm{N}^{\circ}$ of EPs & 12 & 18 & 17 & 0.4013 \\
\hline $\mathrm{N}^{\circ}$ of cancelled procedures & 93 & 10 & 8 & 0.0608 \\
\hline $\mathrm{N}^{\circ}$ of requested albeit not transplanted corneas & 5 & 4 & 0 & 0.0302 \\
\hline $\mathrm{N}^{\circ}$ of waisted grafts & 282 & 139 & 65 & 0.0403 \\
\hline
\end{tabular}

$P K$ penetrating keratoplasty; $A L K$ Anterior lamellar keratoplasty; $E K$ endothelial keratoplasty

lockdown period, as for the Italian Government declaration), elective surgeries in all specialties, ophthalmology included, have been suspended in the majority of cases in order to avoid SARS-CoV-2 spreading. (Buonomo et al. 2020) A dramatic reduction in the number of keratoplasties derived, with at least 2 main related consequences.

First of all, the Eye Bank organization works as a complex structure responsible for collection, evaluation, preservation and distribution of corneal tissue. (Chaurasia et al. 2020) To ensure the proper functioning of this dynamic apparatus, a multitude of clinical and laboratory skills and economic input are required. (Bohringer et al. 2009; Shinozaki et al. 1997) Corneal tissues must be used within a maximum of 34 days from collection and the maximum storage time depends on the preservation technique used: either hypothermic storage $\left(4-6{ }^{\circ} \mathrm{C}\right)$ or organ culture $\left(31-37^{\circ} \mathrm{C}\right)$. The latter is the most commonly used storage technique in Europe and, despite allowing a longer storage time, during the lockdown timeframe in Italy up to 421 corneas available for transplantation were discarded, having not been used before the expiry date, representing a significant waste of resources. (Jones et al. 2009; Parekh et al. 2020) However, it must be noted that, even if in a small number of cases, discarded corneas were used for research purpose, whenever authorized by local ethical committee and in accordance to the donors' will.

Moreover, and perhaps more crucially, the social implications are profound and multifaceted, due to the recent technical innovations introduced in corneal keratoplasty and the notable impact of functional visual improvement transplants can provide in the majority of cases. (Dunker et al. 2020; Woo et al. 2019) Thus, used grafts at this time is a significant loss to the potential benefits if could have given the recipients.

Until now, the COVID-19 pandemic has harmed the overall corneal transplant activity across Italy, with a reduction of nearly $60 \%$ as compared to the same period of 2019. This obvious decrease has been mainly due to the profound reorganization of the national health service leading to the conversion of operating theatres into intensive care unit wards, permitting only urgent surgeries.

Surprisingly, a slight increase in the number of exported grafts $(15 \%)$ has been reported during the analysed timeframe of 2020. This apparently counterintuitive evidence might be explained by the fact that Italy was the first European country to be subjected to COVID-19 lockdown rules, while the corneal transplant activities unrestrictedly went on in different other parts of Europe.

The current available data are representative of a whole nation Eye Bank establishment and may be considered suggestive not only of the present but especially of the forthcoming difficulties the Eye Bank facilities are going to experience. Hence, it is advisable a general re-arrangement of the Eye Bank institutions all around the world will be carried out, as the current pandemic is exposing the frailty of an already vulnerable system. In addition, since the current evolving pandemic is determining gross 
restrictions in corneal graft availability, ophthalmologists will need to use even more stringent prioritisation criteria to select host patients to treat in accordance to visual residue, age and functional need.

Funding Open access funding provided by Università degli Studi di Roma Tor Vergata within the CRUI-CARE Agreement. No funding sources were required for the production of this manuscript.

\section{Declarations}

Conflict of interests The authors declare no conflict of interest.

Open Access This article is licensed under a Creative Commons Attribution 4.0 International License, which permits use, sharing, adaptation, distribution and reproduction in any medium or format, as long as you give appropriate credit to the original author(s) and the source, provide a link to the Creative Commons licence, and indicate if changes were made. The images or other third party material in this article are included in the article's Creative Commons licence, unless indicated otherwise in a credit line to the material. If material is not included in the article's Creative Commons licence and your intended use is not permitted by statutory regulation or exceeds the permitted use, you will need to obtain permission directly from the copyright holder. To view a copy of this licence, visit http://creativecommons.org/licenses/by/4.0/.

\section{References}

Aiello F, Gallo Afflitto G, Mancino R, Li JO, Cesareo M, Giannini C, Nucci C (2020) Coronavirus disease 2019 (SARS-CoV-2) and colonization of ocular tissues and secretions: a systematic review. Eye (Lond). https://doi. org/10.1038/s41433-020-0926-9

Bohringer D, Maier P, Sundmacher R, Reinhard T (2009) Costs and financing. A cost calculation of an up-to-date eye bank in Germany. Dev Ophthalmol 43:120-124. https://doi.org/ $10.1159 / 000223845$

Buonomo OC, Materazzo M, Pellicciaro M, Caspi J, Piccione E, Vanni G (2020) Tor Vergata University-hospital in the beginning of COVID-19-Era: experience and recommendation for breast cancer patients. Vivo 34:1661-1665

Busin M, Yu AC, Ponzin D (2020) Coping with COVID-19: an italian perspective on corneal surgery and eye banking in the time of a pandemic and beyond. Ophthalmology. https://doi.org/10.1016/j.ophtha.2020.04.031
Chaurasia S, Sharma N, Das S (2020) COVID-19 and eye banking. Indian J Ophthalmol 68:1215-1216. https://doi. org/10.4103/ijo.IJO_1033_20

Dunker SL et al (2020) Descemet membrane endothelial keratoplasty versus ultrathin descemet stripping automated endothelial keratoplasty: a multicenter randomized controlled clinical Trial. Ophthalmology. https://doi.org/10. 1016/j.ophtha.2020.02.029

Gain P, Jullienne R, He Z, Aldossary M, Acquart S, Cognasse F, Thuret G (2016) Global Survey of Corneal Transplantation and Eye Banking. JAMA Ophthalmol 134:167-173. https://doi.org/10.1001/jamaophthalmol.2015.4776

Istituto Superiore di Sanità (2020) Aggiornamento delle misure di prevenzione della trasmissione dell'infezione da nuovo Coronavirus (SARS-CoV-2) in Italia attraverso il trapianto di organi e tessuti. Gazzetta Ufficiale

Jones GLA, Ponzin D, Pels E, Maas H, Tullo AB, Claerhout I (2009) European Eye Bank Association. Dev Ophthalmol 43:15-21. https://doi.org/10.1159/000223835

Olivia Li JP et al (2020) Preparedness among Ophthalmologists: During and Beyond the COVID-19 Pandemic. Ophthalmology 127(5):569-572. https://doi.org/10.1016/j.ophtha. 2020.03.037

Parekh M et al (2020) Impact of COVID-19 on corneal donation and distribution. Eur J Ophthalmol. https://doi.org/10. $1177 / 1120672120948746$

Romano MR et al (2020) Facing COVID-19 in Ophthalmology Department. Curr Eye Res 45(6):653-658. https://doi.org/ 10.1080/02713683.2020.1752737

Shinozaki N, Shimazaki J, Tsubota K (1997) Cost Effectiveness in Japanese Eye Banks. Cornea 16:243-244

Società Italiana Banche degli Occhi (2000) Statuto della Società Italiana Banche degli Occhi vol 76137. Italy

Vanni G et al (2020) Effect of lockdown in surgical emergency accesses: experience of a COVID-19 hospital. Vivo 34(5):3033-3038. https://doi.org/10.21873/invivo.12137

Vanni G, Pellicciaro M, Materazzo M, Palombi L, Buonomo OC (2020) breast cancer diagnosis in coronavirus-era: alert from Italy. Front Oncol. https://doi.org/10.3389/fonc.2020. 00938

Woo JH, Ang M, Htoon HM, Tan D (2019) Descemet membrane endothelial keratoplasty versus descemet stripping automated endothelial keratoplasty and penetrating keratoplasty. Am J Ophthalmol 207:288-303. https://doi.org/ 10.1016/j.ajo.2019.06.012

Zhu $\mathrm{N}$ et al (2020) A novel coronavirus from patients with pneumonia in China 2019. N Engl J Med 382:727-733. https://doi.org/10.1056/NEJMoa2001017

Publisher's Note Springer Nature remains neutral with regard to jurisdictional claims in published maps and institutional affiliations. 